\title{
Some Observations on Microsyntactic Units and Discourse Grammar of Kam
}

\author{
Mousa A. Btoosh \\ Department of English Language and Translation, Fahad bin Sultan University, Tabuk, KSA \\ Email: mousa.btoosh@gmail.com
}

How to cite this paper: Btoosh, M. A. (2018). Some Observations on Microsyntactic Units and Discourse Grammar of Kam. Open Journal of Modern Linguistics, $8,108-125$. https://doi.org/10.4236/ojml.2018.84012

Received: June 9, 2018

Accepted: August 4, 2018

Published: August 7, 2018

Copyright $\odot 2018$ by author and Scientific Research Publishing Inc. This work is licensed under the Creative Commons Attribution International License (CC BY 4.0).

http://creativecommons.org/licenses/by/4.0/

(c) (i) Open Access

\begin{abstract}
This study aims to shed light on the microsyntactic units and discourse grammar of Kam, a language spoken in Guizhou, Hunan and Guangxi Provinces in China. To this end, the paper explores the use and functions of particles and classifiers, and how the discourse grammar elements operate across sentences to create texture, cohesion and convey the sender's communicative intent. The corpus of this study consists of two short stories in addition to some other illustrative examples. Findings show that particles in Kam are used to mark unity and serve pragmatic presuppositions and assertions. Results also indicate that Kam, which features neither wh-movement nor subject-verb inversion in questions, uses particles to express interrogation, aspect and modality. Additionally, the findings reveal that nominal classifiers have less semantic limitations than the verbal ones. Finally, it has been observed that predicates don't require the phonological appearance of their subjects as long as they are understood contextually.
\end{abstract}

\section{Keywords}

Kam, Discourse, Particles, Classifiers, Cohesion, Communication, Grammar

\section{Introduction and Review of Literature}

Irrespective of the pivotal role of context which makes up the universe of communication, understanding or figuring out what is meant first requires a close inspection of what is literally said or written as the sender's goals are often embodied in the words and expressions s/he uses. On the whole, much of the linguistic information in natural languages is carried out by lexical items or lexemes. Yet, considerable differences are shown to exist among languages in this regard. For instance, some languages, including Kam, heavily depend on grammatical morphemes (i.e. particles and classifiers) to serve prime expressive, 
communicative and discourse functions.

It should be highlighted that particles in Kam are non-inflectional free morphemes. Still, they have no lexical meanings by themselves. Rather, they have grammatical functions based on the context of usage. Along with particles, Kam is rich in classifiers, which can be divided into two main categories, namely, nominal and verbal. Nominal classifiers are used to indicate units of people and things whilst the verbal ones are used to express the number of times an action takes place. Unlike grammatical particles and classifiers whose domain scope is limited to the sentence level, accounting for discourse grammar elements requires looking at some features and constraints that govern the flow of sentences or utterances. No doubt, this necessitates moving from the sentence level to the discourse at large.

Commencing with the first introduction of the term "discourse analysis" into the linguistics field by Zelling Harris in 1952, linguistic research has shifted from microlinguistics and structuralism to macrolinguistics and functionalism. Consequently, discourse analysis is primarily devoted to examining the language features that cross sentence boundaries. Discourse, whether oral or written consists of two main components, viz., propositional content or discourse and metadiscourse devices (discourse about discourse). Whereas the first component refers to what a sender (writer/speaker) writes/ says, the second one, on the other hand, refers to what a sender thinks about what s/he writes/says (Skelton, 1988; Btoosh, 1999, among others). Research on discourse analysis has demonstrated the validity of metadiscourse devices/discourse markers in organizing the discourse, getting receiver's attention, engaging and persuading the receiver (reader/hearer) and clarifying the sender's attitudes towards the propositional content and the receiver simultaneously.

Unlike discourse analysis, which is communicative-oriented, discourse grammar that has been pushed to the fore as a result of the expanding scope of the former is structure-oriented. Describing and analyzing syntactic structures, together with discourse-grammar interface, constitute the primary focus of discourse grammar. According to van Leusen (2007: p. 12), discourse grammar is a branch of the discourse theory, which rests on the idea that "discourse is composed of clauses and larger discourse units just like sentences are composed of words and phrases." In other words, discourse grammar studies the effect of grammar on the discourse and that of the discourse on grammar (Chu, 1998). For Gleason (1965), discourse grammar is more insightful and economical than sentence grammar. Grimes (1975) believes that discourse grammar is mainly devoted to the potential functions that grammatical constituents may serve in the discourse:

Our grasp of grammar has changed sufficiently in the past decade that instead of simply saying that a language has, for example, thirty-two clause types, we can now ask legitimately what the various clause types are for, and by tracing their pattern of use within a discourse we can get an answer (p. 97). 
Unlike English, which stands out as the most studied language in the world, Kam is much less fortunate in this regard. Despite the serious attempts carried out by a number of linguists during the last seven decades, the linguistic research on Kam is still below ambition and at the initial stage. As far as the researcher is aware, the history of Kam linguistic research dates back to the very end of 1941 and the beginning of 1942 when Li Fanggui surveyed the Kam in the southern areas of Guizhou Province. Since then, however, a number of studies have been carried out to survey and investigate this language.

In their efforts to explore this variety, Edmondson and Yang $(1988,1993)$ and Yang and Edmondson (1997) addressed numerous phonetic and phonological aspects of Kam, along with its history in the ancient times. Passing to matters more closely related to dialectology, the Chinese Academy of Sciences published the Final Report Surveying Kam Dialects in 1957. This report has until fairly recently been considered the most comprehensive linguistic source about Kam. In a study entitled A Brief Description of the Kam Language, Min (1980) provides an exploratory description of this variety. The importance of Min's study stems from its attempt to account for numerous aspects of the variety, including phonology, morphology, grammar, orthography and lectal variation.

Drawing on the literature, no comprehensive study has been conducted on Kam since the publication of the Final Report Surveying Kam Dialects in 1957 apart from The Dong Language In Guizhou Province, China, a study conducted by Long \& Zheng (1998). This study provides a detailed analysis and description of Kam's culture and language. Kam's conversational sequences and techniques (as used in telephone conversations) were also a subject of investigation by Rakhieh \& Abbadi (2014). More recently, Yang (2017) conducted a thorough study on the structural properties of this variety based on the functions they serve in various aspects of its narrative discourse.

It is rather apparent from the foregoing literature that the scope of the linguistic research on Kam is so restricted that it has rarely gone beyond the sentence level. Focusing on microsyntactic units and discourse grammar of Kam, this paper takes dual steps towards shedding light on particles, classifiers and discourse markers and delineating the use and functions that such devices serve in the discourse.

It is worth mentioning that the author was first introduced to the variety under investigation (Kam) through the graduate "Filed Methods" courses offered at the University of Texas at Arlington. These courses provide learners with hands-on, real-life experience in the task of investigating a language through one-on-one interviews with its speakers. Yet, the choice of the topic itself is attributed to the exceptional status and role that particles, classifiers and cohesive devices play in this variety.

\section{Methodology}

To have a fairly clear and comprehensive idea about particles, classifiers and 
discourse grammar of Kam, two aims, as mentioned earlier, have been set for analysis in this study. The first section is devoted to examining microsyntactic units, particularly, particles and classifiers. The second section, on the other hand, focuses on the discourse grammar elements and the grammatical aspects of literary cohesion, including the referring expressions, repetition, ellipsis, conjunctions and the structure of information as used in the literary texts of Kam. The study is primarily based on two short stories, viz. the "Three Friends" and "Animals Steal the Plant Seeds"; both stories are transcribed in Kam orthography.

In conformity with the aims posited above, the data underwent a number of analytical procedures and steps. These include:

1) Identifying and classifying grammatical and discourse particles and classifiers according to their grammatical and discourse functions; \&

2) Extracting, classifying and analyzing the aspects of literary cohesion markers (referring expressions, repetition, ellipsis, conjunctions, and discourse relations) based on their contextual discourse functions.

\section{Microsyntactic Units: Forms and Functions}

\subsection{Particles}

On closer inspection of the data below, it emerges clearly that Kam is enormously rich in particles. The frequent usage of particles, as a matter of fact, could be attributed to the different syntactic, semantic and discourse functions they possess in this particular variety. Understanding the differences between particles requires taking the functional notion into account; the functions of particles in Kam, as illustrated in the following subsections, range from "asking for information", through "seeking confirmation", "asking for involvement", "expressing aspect and interrogation", "conveying modality", to "coding pragmatic presuppositions and assertions".

(1)

\begin{tabular}{llllllll}
\multicolumn{2}{l}{ A. Wordform: jav } & lagx mags & jas & guanl & mangc & ac? \\
WfGloss: & so & child big & that & name & what & QUES \\
WfPOS: & conj & comm adj int & mkr & $\mathrm{v}$ & pro & part
\end{tabular}

Free Translation (FT, henceforth): What's the name of your older child?

\begin{tabular}{|c|c|c|c|c|c|c|c|c|}
\hline \multicolumn{4}{|c|}{ B. Wordform: danglxul xic } & jav, & meec & yaoh & naengl & yaoh \\
\hline \multirow{2}{*}{$\begin{array}{l}\text { WfGloss: } \\
\text { WfPOS: }\end{array}$} & \multicolumn{2}{|c|}{ long ago } & time, season & that & have & in, at, on & in still & in, at, on \\
\hline & ac & & comm & dem & $\mathrm{v}$ & prep & $\operatorname{adv}$ & prep \\
\hline vangv & yeml & juc & $\operatorname{liax}$ & & meec & meec & yingc & doc \\
\hline ide & shady & $\begin{array}{l}\text { as y } \\
\text { kno }\end{array}$ & $\begin{array}{l}\text { asking } \\
\text { respon }\end{array}$ & & have & have & several & animat \\
\hline $\mathrm{omm}$ & adj int & par & part & & $\mathrm{v}$ & $\mathrm{v}$ & num & CLS \\
\hline
\end{tabular}


hoh hangc lagx nuns map douc guangl jac, hov

group kind; typechild young come come in bright sort of you are right

CLS CLS comm adj $\mathrm{v} \quad \mathrm{v}$ adjint part adv

FT: Long time ago, there were several children in the other world who were going to come into this world (to be born).

\begin{tabular}{|c|c|c|c|c|c|c|}
\hline \multicolumn{2}{|c|}{ C. Wordform: bens } & jal & yingc & jagc & nyenc & xeengl \\
\hline WfGloss: & only & leave & several & general clf & person & row \\
\hline WfPOS: & $\mathrm{adv}$ & $\mathrm{v}$ & num & CLF & comm & $\mathrm{v}$ \\
\hline lol & jas & liiuc & lis & jiuc & gh. & \\
\hline boat & that & save & modal & CLF & & \\
\hline comm & dem & $\mathrm{v}$ & part & CLF & $\mathrm{am}$ & \\
\hline
\end{tabular}

FT: Only a few fishermen remained alive.

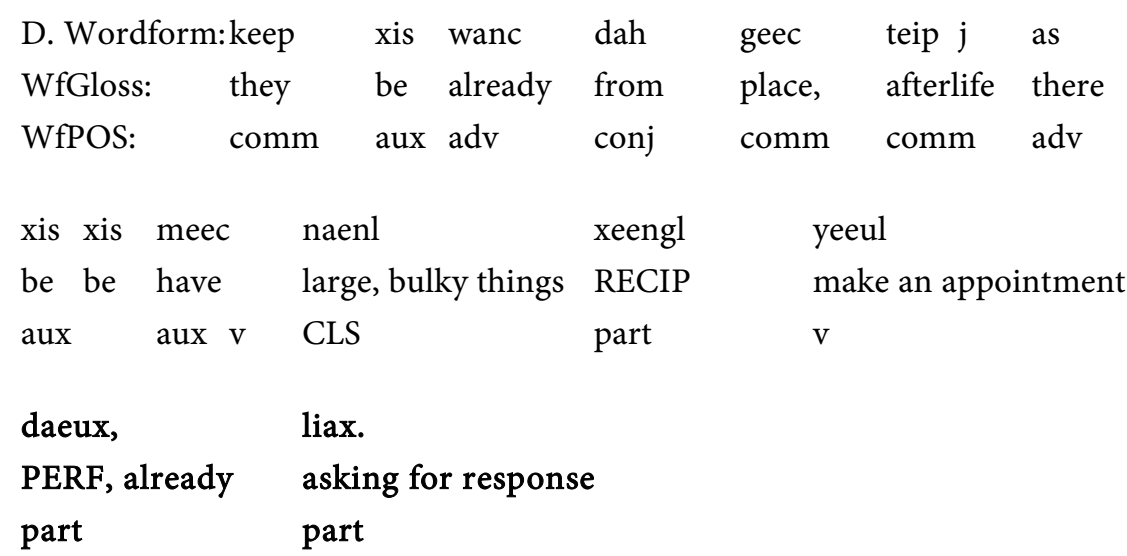

FT: They reached an agreement from the very beginning.

$\begin{array}{llllll}\text { E. Wordform: } & \text { maoh } & \text { wanc } & \text { songv } & \text { biinl } & \text { jiuc } \\ \text { WfGloss: } & 3 \mathrm{~S} & \text { already } & \text { put down } & \text { beside } & \text { bridge } \\ \text { WfPOS: } & \text { pro } & \text { adv } & \text { v } & \text { adv } & \text { comm }\end{array}$

$\begin{array}{lll}\text { jas } & \text { laoc } & \text { lus } \\ \text { there } & \text { PERF } & \text { Part of fact confirming } \\ \text { adv } & \text { part } & \text { part }\end{array}$

FT: He had already placed those sticks on the side of the bridge.

\begin{tabular}{lllllll}
\multicolumn{2}{l}{ F. Wordform: jagx } & naih & haeix & leix & mangc & gangs, \\
WfGloss: & abstract & this & not & words & what & speak, talk \\
WfPOS: & mkr & dem & neg & comm & pro & v
\end{tabular}

iv,

extreme surprise

part

FT: We are speechless about all this. 


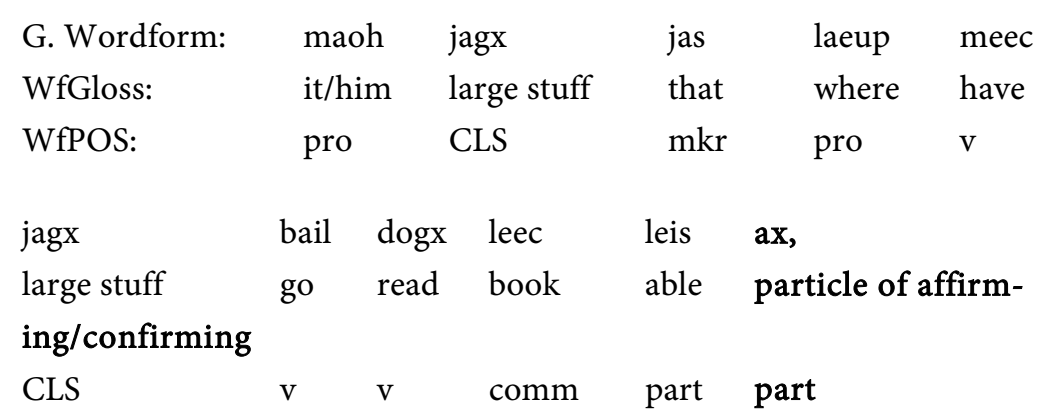

FT: but he had no way to afford to go to school.

$\begin{array}{lllllll}\text { H.Wordform: nyac } & \text { maenlnaih } & \text { lis } & \text { ouxmaenl } & \text { mix } & \text { ac } \\ \text { WfGloss: } & 2 S & \text { today } & \text { have } & \text { comm } & \text { NEG } & \text { QUES } \\ \text { WfPOS: } & \text { pro } & \text { adv } & \text { v } & \text { v } & \text { par } & \text { part }\end{array}$

FT: Have you had lunch?

$\begin{array}{llllll}\text { I. Wordform: } & \text { naenl } & \text { naih } & \text { weex } & \text { geis } & \text { luh } \\ \text { WfGloss: } & \text { CLS } & \text { this } & \text { do } & \text { unable } & \text { suggestion/warning } \\ \text { WfPOS: } & \text { CLS } & \text { dem } & \text { aux } & \text { modal } & \text { Part }\end{array}$

FT: Don't do this! This is undoable.

The excessive reliance of Kam on particles in the above examples (1A-1I) aptly illustrates the weight and important roles that such devices possess in the syntax and discourse structure of Kam. As can be seen, there are two sets of particles, namely, grammatical and discourse. The following two subsections are devoted to gaining a better understanding of these particles, along with their contextual functions.

\subsubsection{Grammatical Particles}

Grammatical particles make up one of the largest word classes in this variety. Indisputably, their significance cannot be exaggerated as they offer much expressive power at the utterance or sentence level. On the face of it, they are extensively used to express interrogation, aspect and modality.

\section{1) Interrogative Particles}

Interrogative sentences in Kam feature neither wh-fronting nor subject-verb inversion. As a consequence, such sentences typically end in particles signaling the speaker's desire to seek information from the questioned receiver. Typical examples of this phenomenon can be seen in $(1 \mathrm{~A})$ and $(1 \mathrm{H})$. In these examples, we can see that the particle $a c$ is placed at the end of the sentence to fulfill the interrogative function. Many other particles such as ax, bac, and eel are used to express interrogation as well.

Besides the particles signaling the speaker's desire for information, Kam is rich of particles signaling the speaker's desire to get a confirmation of the propositional content of the utterance, as shown in (2).

(2) 




FT: "You know how to row a boat, come on, don't you ?", the oldest one said.

It is worth noting that tag questions in Kam are not different from those used in English in terms of function; they are merely used when the speakers are practically certain about the response, but they are just seeking a confirmation of their statements. However, it is apparent that word order in this variety remains unchanged in all types of questions.

\section{2) Aspect Particles}

Turning back to the particles exemplified in (1), it is evident that the sentence-final particles used in (1D) and (1E) are meant to express the perfective aspect. In these examples, unless the particles daeux and laoc are used, perfective-imperfective distinction remains impossible. The following examples introduce some other particles used to express perfective in Kam.

(3)

$\begin{array}{llllllll}\text { A. Wordform: } & \text { gaeis } & \text { xis } & \text { ac } & \text { keep } & \text { xus } & \text { bail } & \text { lac } \\ \text { WfGloss: } & \text { NEG } & \text { be } & \text { two they } & \text { then } & \text { go } & \text { PERF } \\ \text { WfPOS: } & \text { adv } & \text { aux } & \text { num } & \text { comm } & \text { adv } & \text { v } & \text { asp }\end{array}$

FT: That was it and they went on.

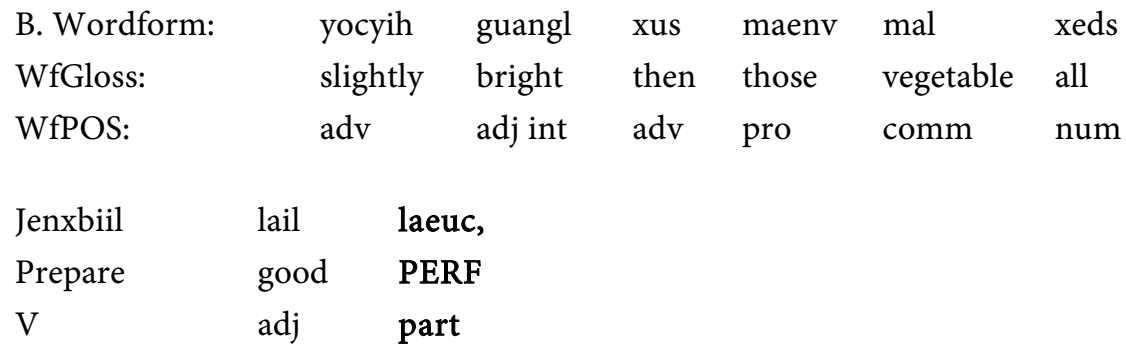

FT: All the food was ready at dawn.

The particles lac and laeuc indicate the completion of the acts bail "go" and jenxbiil "prepare". It is also not difficult from the examples presented above to tie together the perfective aspect particles with events of short duration.

\section{3) Modality Particles}

In Kam, modality is expressed by particles, too. Nevertheless, it should be mentioned that modality meanings expressed by particles in Kam are heavily restricted compared to the wide range of meanings associated with modality in most languages all over the world. As shown in (1C) and (1I), modality particles such as lis are used to express either ability or disability. Once again, the use of 
particles to express mood reflects the weaknesses of Kam's verbs to fulfill this function.

\subsubsection{Discourse Particles}

Besides grammatical particles, Kam is abundant in discourse particles, which are mainly used to express agreement, uncertainty, suggestions, pauses, anxiety and supposition. Accordingly, discourse particles do not contribute much to the propositional content of the utterances. Rather, they are used to convey various attitudes and direct or redirect the flow of conversation. In other words, discourse particles are employed to convey the speaker's stance or state of knowledge. As a general remark, grammatical particles occur at sentence level, as this is normal environment for them to fulfill their functions. Discourse particles, which contribute much to organizing and structuring the discourse, need an environment that goes beyond the sentence level. It is important to note that discourse particles usually have strong attitudinal or emotional component, an issue that reflects more complex workings on the levels of cognition, semantics and pragmatics (Parrott, 2001: p. 1). Thus, the communicative intent of the sender significantly affects the choice of the linguistic/discourse devices.

Example (1B), for instance, presents three discourse particles that realize distinct pragmatic functions. The first two particles juc "as you know" and liax "asking for response", which have nothing to do with sentence structure, are used to request the receivers' involvement and to show that the sender's message is a fact rather than an opinion. By using such particles, the sender assumes that the receiver already knows and accepts, as part of mutual knowledge, the propositional content of the sentence or utterance. Consequently, the ultimate goal of using such particles is to make the receiver take the conveyed propositional content for granted.

Another feature characterizing the discourse in Kam is the use of pause particles such as dil and ac. In the context of pause particles, it is worth mentioning that these particles can be seen as either signals to improve comprehension or traces of production difficulties (Bestgen, 1998). Yet, sometimes, pause particles are purposely used to inform the listener about the presence of a topic or even a topic shift. Moreover, speakers sometimes resort to pause particles when they need to have a time to think of what to say in their turns and at the same time to hold their turn in the conversation, as shown in (4).

(4)

$\begin{array}{lllllll}\text { Wordform: } & \text { laos } & \text { eanc } & \text { naih } & \text { bail } & \text { heemx } & \text { dil } \\ \text { WfGloss: } & \text { enter } & \text { house } & \text { this } & \text { go } & \text { call (a person) } & \text { pause } \\ \text { WfPOS: } & \mathrm{v} & \text { comm } & \text { dem } & \mathrm{v} & \mathrm{v} & \text { part }\end{array}$

FT: As he went into one of those guys' house to call.

In addition to the pause particles mentioned above, Kam sometimes uses metadiscourse particles that fulfill a dual purpose of unifying the text and express- 
ing the speaker's intent or attitude towards the propositional content, as illustrated in (5A and $\mathrm{B})$.

(5)

\begin{tabular}{|c|c|c|c|c|c|}
\hline A.Wordform: & iv & gaoclaoc & jav & yuh & bail \\
\hline WfGloss: & extreme surprise & married man & then & $\begin{array}{l}\text { again, } \\
\text { then }\end{array}$ & go \\
\hline WfPOS: & part & comm & $\mathrm{adv}$ & $\mathrm{v}$ & $\mathrm{v}$ \\
\hline
\end{tabular}

FT: "Wow", that man then went to take a look and...

$\begin{array}{llllll}\text { B.Wordform: } & \text { maoh } & \text { yuh } & \text { nyenh } & \text { yox } & \text { liax } \\ \text { WfGloss: } & 3 S & \text { again, then } & \text { also } & \text { know } & \text { asking for response } \\ \text { WfPOS: } & \mathrm{v} & \text { adv } & \text { adv } & \text { v } & \text { v }\end{array}$

FT: He also knew the situation well, right?

Based on the context of usage, the two particles used above (iv and liax) are functionally metadiscourse devices as they do not add anything to the propositional content itself. Rather, they just clarify the sender's attitude towards the propositional content and/or the receiver. It may go without saying that the use of liax is prerogative to the narrator. That is, only the narrator has the privilege of using it (Diller, Edmondson, \& Luo, 2008). To sum up, particles in Kam fulfill several functions at sentence and discourse levels.

\subsection{Classifiers}

On the basis of the examples presented below, there are two sets of classifiers in Kam, viz., nominal and verbal classifiers. The distinction between the two categories is made based on "the closeness of their relationships with a verb or a noun.” (Lu, 2012: p. 230).

\subsubsection{Nominal Classifiers}

As shown in (6), classifiers typically follow numerals when placed before head nouns. Furthermore, classifiers and head nouns are juxtaposed in adjacent positions and not separated by any other element ( $\mathrm{Lu}, 2012)$.

(6)

$\begin{array}{lllllll}\text { A. Wordform: } & \text { deic } & \text { wul } & \text { menl } & \text { dil } & \text { xebc } & \text { naenl } \\ \text { WfGloss: } & \text { disposable } & \text { above } & \text { sky } & \text { genitive } & \text { ten } & \text { CL thing } \\ \text { WfPOS: } & \mathrm{v} & \text { adv } & \text { comm } & \text { part } & \text { num } & \text { CLF } \\ & & & & & & \\ \text { dalmaenl } & \text { daengl } & \text { beengv } & \text { dogl } & \text { jus } & \text { naenl } & \text { bail. } \\ \text { sun } & \text { come } & \text { shoot } & \text { down } & \text { nine } & \text { CL thing go } \\ \text { comm } & \mathrm{v} & \mathrm{v} & \text { adv } & \text { num } & \text { CLF } & \text { trans }\end{array}$

FT: They shot down nine of the ten suns.

B. Wordform: keep xus dah wul sedl nguap 


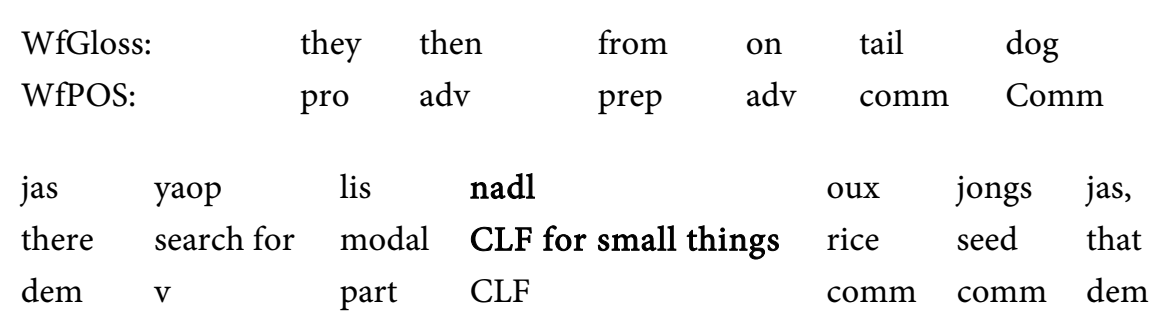

FT: They found the rice seed on the dog's tail.

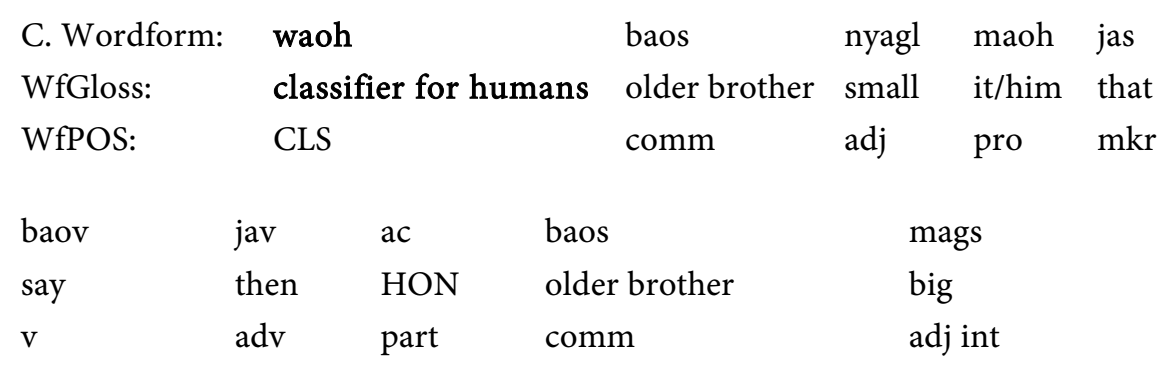

FT: The younger brother, he said: my big brother.

\begin{tabular}{|c|c|c|c|c|c|c|}
\hline D. Wordform: & xus & daeic & jag & & sedl & seisgal \\
\hline WfGloss: & then & hold & & eneral, large stuf & tail & self \\
\hline WfPOS: & $\mathrm{adv}$ & $\mathrm{v}$ & CL & & comm & ref \\
\hline jas & daengl & & $\mathrm{nl}$ & pangp & pangp & jas, \\
\hline that & come & & url & high & high & that \\
\hline dem & $\mathrm{v}$ & r & & adj & adj & dem \\
\hline
\end{tabular}

FT: So (he) held (his) own tail curled up high.

Kam's richness in classifiers is readily observed from the above examples. However, what makes the situation more complex is the use of such classifiers in complementary distribution. Thus, different classifiers are used with different categories of things. General classifiers such as naenl are used for a wide range of things and they do not indicate a particular kind of objects (Long \& Zheng, 1998). Specific Classifiers, on the other hand, can be classified into at least four subcategories depending on their domain.

a) Classifiers for humans: $j a g x /$ waoh

b) Classifiers for small things: $\mathrm{dagc}_{\mathrm{C}}$ nadl

c) Classifiers for parts: mangv/seec

d) Classifiers for meals: denv

When nominal classifiers are used to indicate numbers (of things), they combine with numerals to form numeral-classifier phrases such as jus naenl, as exemplified in (6A). Looking more closely at numeral-classifier phrases in Kam, it becomes clear that they are normally situated ahead of the nouns they modify (Long \& Zheng, 1998: p. 94).

eac duc guic 


$$
\begin{aligned}
& \text { two CLS buffaloes } \\
& \text { "two buffaloes" }
\end{aligned}
$$

Drawing on the following example, it is rather inferred that the sender, guided by his/her communicative intent, uses reduplication to realize his/her actual intent. Classifiers can be generally reduplicated to express the meaning of each member/unit of the group.

(8)

\begin{tabular}{lclclr} 
a. naenl & naenl & b. loiv & loiv & c. denv & denv \\
CLS & CLS & CLS & CLS & CLS & CLS \\
each/every one & \multicolumn{2}{l}{ each/every pair } & \multicolumn{2}{l}{ each/every meal }
\end{tabular}

\subsubsection{Verbal Classifiers}

Generally speaking, classifiers are not typically verbal. Still, a classifier is called verbal if the event-denoting expression is verbal. The usage of some verbal classifiers is often restricted by the semantic properties of the verbs they co-occur with whilst noun classifiers have less semantic limitations. Unlike nominal classifiers, verbal classifiers are measures for verbs of action that express the number of times and action takes place (Chao, 1968).

(9)

$\begin{array}{llll}\text { Wordform: } & \text { biiul } & \text { saml } & \text { dads } \\ \text { WfGloss: } & \text { jump } & \text { three } & \text { CLS } \\ \text { WfPOS: } & \text { v } & \text { NUM } & \text { CLS }\end{array}$

FT: jump three times

It is also even common in Kam to use verbs as classifiers, as in (10).

(10)

$\begin{array}{llll}\text { Wordform: } & \text { huaik } & \text { yingc } & \text { huaik } \\ \text { WfGloss: } & \text { wave } & \text { several } & \text { wave } \\ \text { WfPOS: } & \text { v } & \text { NUM } & \text { CLS }\end{array}$

FT: wave several times

\section{Discourse Structure}

A discourse whether oral or written is not just a sequence of fragmented utterances or sentences. On the contrary, it must exhibit a kind of coherence, consistency and continuity, a matter that is clearly reflected by inter-sentential or interclausal relationships. Recent proposals on discourse analysis have shown that a discourse must have some cohesive devices and connectors that help create texture and make it a unified whole. Despite the shared cohesive devices, spoken and written discourses do differ in certain aspects especially those dealing with prosodic devices. 
Since discourse structure is best described in the context of the whole discourse, the criteria of sentence acceptability are, to a large extent, different from those of the discourse. To be more precise, a sentence is judged to be wrong if it has a morphological, lexical, syntactic or semantic error. As for discourse, the idea is entirely different. A combination of well-formed sentences can never lead to a well-formed discourse unless such combination follows certain discourse principles. According to Trappes-Lomax (2000: p. 1), there are two broad discourse principles, viz., consistency and cohesion.

The root meaning of consistency is "stand together" or "be in agreement". Textual unity, according to Horning (1991: p. 5), can be achieved through:

a) consistency of context of situation (speaker, hearer, setting, etc.)

b) consistency of function (i.e. predominant communicative purpose)

c) consistency of topic (what participants perceive the discourse as being about)

d) consistency of register (the more or less predictable linguistic choices reflecting the above)

The root meaning of cohesion, on the other hand, is "sticking together". For Halliday and Hasan (1976), cohesion refers to a range of possibilities for linking something with what has gone before. There are several devices used to express cohesion.

a) devices which indicate identity of reference (co-reference) or similarity of reference (comparison):

- determiners and demonstratives: this, that, another...etc.

- pronouns (she, he, it, they, etc.)

b) devices which indicate the nature of meaning between clauses and sentences and larger discourse units (conjunctions):

- additive links (and, moreover, furthermore, etc.)

- temporal links (then, after, later on, etc.)

- adversative links (but, although, nevertheless, etc.)

c) devices that contribute to economy and emphasis:

- ellipsis and substitution

Based on the functions that they typically serve in a discourse, these devices are primarily used to compact the surface text and ensure that the text is composed of a sequence of connected utterances or sentences that form a discourse. The examples presented below demonstrate that referring expressions, ellipsis, substitution, repetition and conjunctions are syntactically licensed in Kam, but their occurrences are governed by discourse-pragmatic constraints.

\subsection{Referring Expressions}

An indicative sign of the effect of discourse on grammar can be manifested in what is called "referring expressions", words whose meaning can be only discovered by referring to other words or elements of context which are clear to both sender and receiver (Cook, 1989). Such expressions or pro-forms, as often called, 
create a chain, linking clauses and sentences together. No doubt, third person pronouns provide a notable example of such expressions in most languages, including Kam. Thus, instead of repeating the full name of a person or a thing, one can just use the pronoun to stand for it except where using such a pronoun leads to confusion or ambiguity. Accordingly, the contextual component of the discourse grammar determines the syntactic structure. Moreover, the use of anaphoric references is governed by the contextual component information. Following are illustrative examples of the referring expressions used in Kam.

(11)



FT: Let me tell you, the other one(married man) also talked about "If not right, no eating?"

$\begin{array}{llllll}\text { B. Wordform: } & \text { ik } & \text { maoh } & \text { nuv } & \text { laenl } & \text { naih } \\ \text { WfGloss: } & \text { shock } & \text { 3S } & \text { see } & \text { object } & \text { this } \\ \text { WfPOS: } & \text { part } & \text { pro } & \text { v } & \text { CLS } & \text { dem }\end{array}$

FT: Hm, he looked at this.

$\begin{array}{lllllll}\text { C. Wordform: } & \text { maoh } & \text { xus } & \text { meec } & \text { nyingl } & \text { naoxsux } & \text { lac } \\ \text { WfGloss: } & \text { it/him } & \text { then } & \text { have } & \text { a bit } & \text { brain } & \text { PERF } \\ \text { WfPOS: } & \text { pro } & \text { adv } & \text { v } & \text { comm } & \text { comm } & \text { asp }\end{array}$

FT: Then he used his brain.

The pronoun maoh in (11B \& C) refers to the same referent (gaoclaoc). It seems obvious that context plays a crucial role in reference resolution in the above three consecutive sentences. Syntactically speaking, a pronoun can never find its antecedent in the same governing category. This proves that the interpretation of some grammatical aspects of a language often goes beyond the sentence level. From a discourse perspective, the use of a pronoun to refer to something or somebody already mentioned creates a kind of chain in which each expression is linked to another. Sometimes, the reference of a pronoun or demonstrative comes out or is deduced from the context rather than from the preceding devices.

\subsection{Repetition}

Repetition is a straightforward cohesive mechanism in most languages. For Cook (1994), repetition of the same nominal can create the same sort of chain as 
pronouns. However, some languages such as English disfavor repeating the same word. This is why they resort to elegant repetition, where synonyms or more general words or phrases are used. It is essential to mention that repetition also varies from one domain to another. In legal discourse, for instance, pro-forms tend to be avoided. However, literary texts often favor repetition over pro-forms (Cook, 1994: p. 31). Irrespective of the variations among languages, repetition performs various pragmatic functions in interactional discourse. According to Rabab'a and Abuseileek (2012), repetition is used to express several functions, including emphasis, clarity, annoyance, persuasion and surprise.

Drawing on the corpus providing the database for this study, it seems that Kam does favor adjacent lexical repetition, but only when it has a rhetorical function.

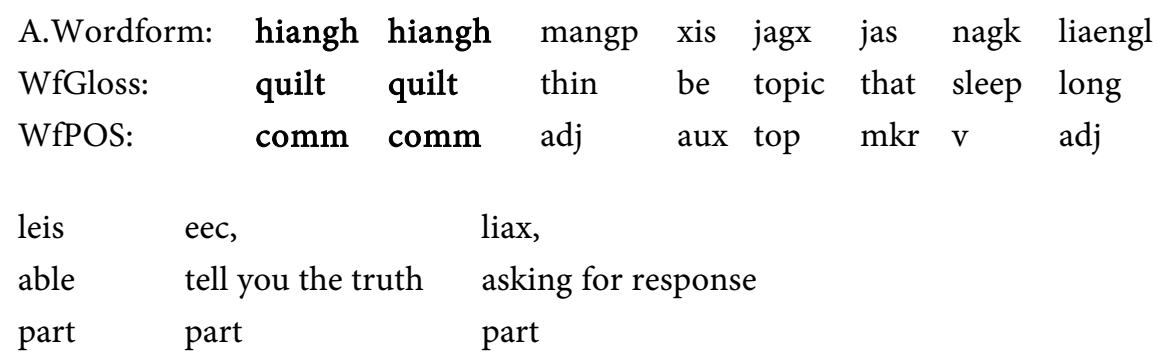

FT: The quilt was thin, and he had no way to sleep long (so he woke up early).

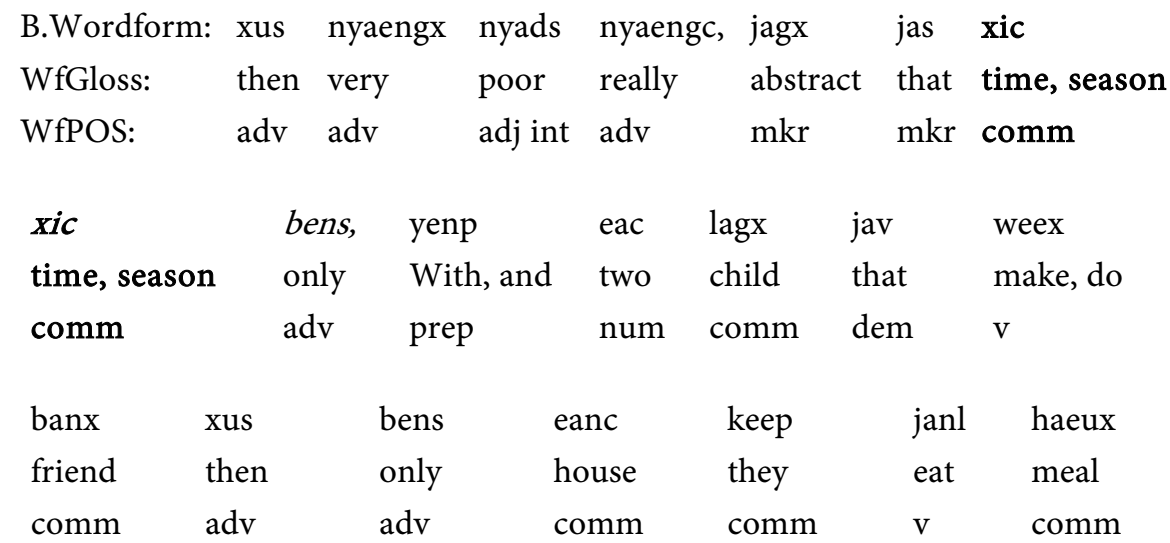

FT: So he was very poor and all the time, he was companion with the other two and had meals at their houses.

As in advertisements, repetition in Kam can be used to attract the receiver's attention to something important, as expressed in (12A). In some other cases, repetition is employed to indicate emphasis, as in (12B). So, adjacent lexical repetition is purposely used here to draw the audience's attention to or multiply the informational foci of something important.

\subsection{Ellipsis}

Like all other kinds of formal links, ellipsis creates cohesion by directing au- 
dience to tie up with other parts of the text since in this case there is no substitution of the deleted words. Oftentimes, predicates in Kam do not require the phonological appearance of their subjects if understood contextually. This phenomenon, which is common in most languages, aims to avoid redundancy as languages rely heavily on the notion of economy. However, this process takes place only when the subject is already introduced in the discourse and its omission does not lead to any kind of ambiguity, as illustrated in the following examples.

(13)

\begin{tabular}{|c|c|c|c|c|c|c|}
\hline A. Wordform: & maoh & jagx & jas & laeup & meec & jagx \\
\hline WfGloss: & $3 S$ & large stuff & that & where & have & large stuff \\
\hline WfPOS: & pro & CLS & $\mathrm{mkr}$ & pro & $\mathrm{v}$ & CLS \\
\hline $\operatorname{dog} x$ & leec & leis & & $a x$ & & \\
\hline read & book & able & & Cor & firmi & /affirming \\
\hline $\mathrm{v}$ & comm & part & & par & & \\
\hline
\end{tabular}

FT: (But) he could not afford to go to school.

$\begin{array}{lllllll}\text { B. Wordform: } & \text { bens } & \text { laeml } & \text { keep } & \text { bail } & \text { dangc } & \text { hagx } \\ \text { WfGloss: } & \text { only } & \text { follow } & \text { they } & \text { go } & \text { place } & \text { inform } \\ \text { WfPOS: } & \text { adv } & \text { v } & \text { comm } & \text { v } & \text { comm } & \text { v }\end{array}$

$\begin{array}{lll}\text { jas } & \text { bail } & \text { nyaoh } \\ \text { there } & \text { go } & \text { live } \\ \text { adv } & \text { V } & \mathrm{v}\end{array}$

FT: (He) only went there to spend time with them.

$\begin{array}{llllllll}\text { C. Wordform: } & \text { deenh } & \text { keep } & \text { bail } & \text { eanc } & \text { janl } & \text { haeux } & \text { xus } \\ \text { WfGloss: } & \text { once } & \text { they } & \text { go } & \text { house } & \text { eat } & \text { meal } & \text { then } \\ \text { WfPOS: } & \text { adv } & \text { comm } & \text { v } & \text { comm } & \text { v } & \text { comm } & \text { adv }\end{array}$

$\begin{array}{ll}\text { dongc } & \text { bail } \\ \text { together } & \text { go } \\ \text { adv } & \text { v }\end{array}$

FT: When they went home to have meals, (he) went with them.

On a closer examination of the above examples, we can see that the related sequential actions are a sequence of clauses with a shared subject deleted in all but the first clause. Consequently, the meaning is still preserved in all the elliptical sentences despite the omission of the noun/pronoun.

\subsection{Conjunction}

Conjunction constitutes another central aspect of the formal links, which are, to some extent, universal. Like other languages, conjunctions in Kam are used to 
conjoin words into phrases, phrases into simple sentences and simple sentences into compound ones, as illustrated in the following examples.

(14)

$\begin{array}{lllllll}\text { A. Wordform: } & \text { nyac } & \text { bail } & \text { hocgail } & \text { yaoc } & \text { bail } & \text { wuc } \\ \text { WfGloss: } & 2 \mathrm{~s} & \text { go } & \text { or } & 1 \mathrm{~s} & \text { go } & \text { Ques } \\ \text { WfPOS: } & \text { pro } & \text { v } & \text { conj } & \text { pro } & \text { v } & \text { part }\end{array}$

FT: You go (there) or let me do that.

$\begin{array}{llllllll}\text { B. Wordform: } & \text { nuv } & \text { jav } & \text { xus } & \text { moah } & \text { gangh } & \text { xun } & \text { lox } \\ \text { WfGloss: } & \text { if } & \text { that } & \text { then } & \text { he } & \text { don't } & \text { speakout } & \begin{array}{l}\text { strong } \\ \text { suggestion }\end{array} \\ \text { WfPOS: } & \text { conj } & \text { demon } & \text { adv } & \text { pro } & \text { aux } & \text { v } & \text { part }\end{array}$

FT: If then, let him be quite.

$\begin{array}{llllll}\text { C. Wordform: } & \text { naenl naih } & \text { xis haeix xus } & \text { xaol weex } & \text { haeix xus } \\ \text { WfGloss: } & \text { CLS this } & \text { be either } & \text { 3s do } & \text { either } \\ \text { WfPOS: } & \text { CLS dem } & \text { aux conj } & \text { you } \mathrm{v} & \text { conj } \\ & & & & & \\ \text { aol } & \text { yenc } & \text { xingh } & \text { daengl } & \text { weex } \\ \text { give } & \text { people } & \text { other } & \text { come } & \text { do } \\ \text { v } & \text { comm } & \text { pro } & \text { do } & \text { v }\end{array}$

FT: Either you do it or let others do it (you need to make a quick decision).

$\begin{array}{lllllllll}\text { D. Wordform: } & \text { jav } & \text { jagx } & \text { jas } & \text { dil } & \text { xis } & \text { waenl liaengl } & \text { daengl } \\ \text { WfGloss: } & \text { so } & \text { large stuff } & \text { that } & \text { pause } & \text { be } & \text { day } & \text { long } & \text { come } \\ \text { WfPOS: } & \text { conj } & \text { CLS } & \text { mkr } & \text { part } & \text { aux } & \text { comm adj } & \text { v }\end{array}$

$\begin{array}{llllllll}\text { xis } & \text { jagx } & \text { jas } & \text { nyenh } & \text { mags } & \text { daeux } & \text { lic } & \text { liax } \\ & \text { large } & \text { that } & \text { also } & \text { big } & \begin{array}{l}\text { PERF, } \\ \text { be } \\ \text { stuff }\end{array} & \text { particle of } & \text { asking for } \\ \text { aux } & \mathrm{v} & \text { mkr } & \text { adv } & \text { adj int } & \text { part } & \text { part } & \text { part }\end{array}$

FT: Well, as day passed and he also grew up.

Conjunctions in each of these four examples (hocgail, nuv, haeix xus and jav) belong to three different sets of conjunctions, namely, additives, causal and subordinating connectives. This, of course, enhances the previous assumption that the grammaticality of a sentence and that of a discourse is not isomorphic.

\section{Structure of Information in Kam}

It would be overhasty to end this section without referring to the structure of information in the narrative discourse of Kam. A careful investigation of the corpus of this study shows that it has a very simple structure with a rising action, climax and falling action. The other crucial point deals with the division of the discourse information into two types: 1) known/background information and 2) 
new information. Of course, a typical universal discourse usually proceeds in this way. However, what is interesting about the structure of information in this story is the frequent usages of discourse markers or particles which indicate that the information is new (markers that indicate the emergence of a new idea). So, it may seem quite common to find a language that uses discourse markers, but it is not so often to find a language where a special kind of particles $(x u s)$ is used to attract the receiver's attention to new information.

(15)

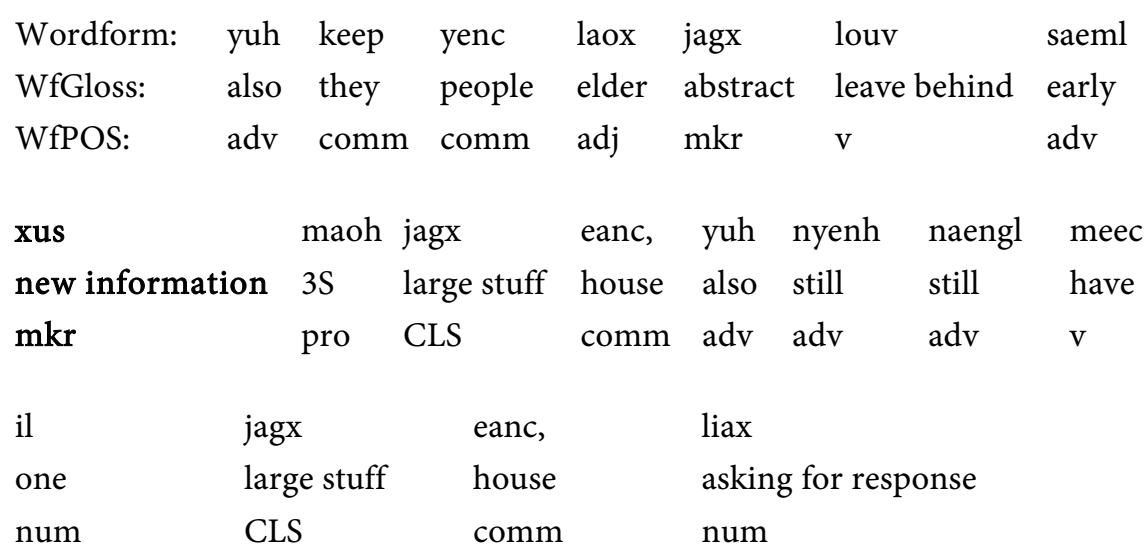

FT: Although his parents passed away early, he still had a house building (to live in).

\section{Conclusion}

This study has looked at the microsyntactic units (particles and specifiers), along with the discourse grammar elements and markers in Kam. An attempt has been made throughout the study to ensure that identifying the reciprocal relation between discourse and grammar is necessary to delineate the effect of the discourse on the careful selection of the grammatical units as well as the functions that grammatical devices might serve in the discourse at large. Findings have explicitly demonstrated that integrating discourse and grammar in the analysis of narrative discourse is essential to pinpoint several aspects of this interwoven relation.

\section{Conflicts of Interest}

The authors declare no conflicts of interest regarding the publication of this paper.

\section{References}

Bestgen, Y. (1998). Segmentation Markers as Trace and Signal of Discourse Structure. Journal of Pragmatics, 29, 753-763. https://doi.org/10.1016/S0378-2166(97)00082-9

Btoosh, M. A. (1999). Hedging in Political Discourse during the Third Gulf War Thalab Al-Sahra. Unpublished Master's Thesis, Jordan: Yarmouk University.

Chao, Y. R. (1968). A Grammar of Spoken Chinese. Berkeley: University of Claifornia 
Press.

Chu, C. (1998). A Discourse Grammar of Mandarin Chinese. New York: Peter Lang.

Cook, G. (1989). Discourse. Oxford: Oxford University Press.

Cook, G. (1994). Discourse and Literature: The Interplay of Form and Mind. Oxford: Oxford University Press.

Diller, A. V. N., Edmondson, J. A., \& Luo, Y. (2008). The Tai-Kadai Languages. London: Routledge Taylor \& Francis Group.

Edmondson, J. A., \& Yang, Q. (1988). Word-Initial Preconsonants and the History of Kam-Sui Resonant Initials and Tone. In J. Edmondson, \& D. Solnit (Eds.), Comparative Kadai: Linguistic Studies beyond Tai (pp. 143-166). Dallas: Summer Institute of Linguistics and University of Texas at Arlington.

Edmondson, J. A., \& Yang, Q. (1993). As Wildflowers Bloom on the Mountainside: A Visit with China's Kam Minority. Journal of Language and Culture, 12, 73-85.

Gleason, H. A. (1965). Linguistics and English Grammar. New York: Holt, Rinehart \& Winston.

Grimes, J. E. (1975). The Thread of Discourse. The Hague: Mouton. https://doi.org/10.1515/9783110886474

Halliday, M. A. K., \& Hassan, R. (1976). Cohesion in English. London: Longman.

Horning, A. (1991). Readable Writing: The Role of Cohesion and Re-Dundancy. Journal of Advanced Composition, 11, 135-145.

Long, Y., \& Zheng, G. (1998). The Dong Language in Guizhou Province, China (N. Geary, trans.) Texas: Summer Institute of Linguistics and University of Texas at Arlington.

Lu, T.-Q. (2012). Classifiers in Kam-Tai Languages: A Cognitive and Cultural Perspective. Boca Raton, FL: Universal Publishers.

Min, L. (1980). Translated: A Brief Description of Kam. Beijing: Nationalities Publishing.

Parrott, L. A. (2001). Discourse Markers, Particles, and Sentential Stress: Interaction on the Level of Information Structure in Russian. Paris: University of Paris.

Rabab'ah, G., \& AbuSeileek, A. (2012). The Pragmatic Functions of Repetition in TV Discourse. Journal of Research in Language, 10, 445-460.

https://doi.org/10.2478/v10015-012-0004-X

Rakhieh, B. M. M. A., \& Abbadi, R. (2014). Conversational Sequences and Dialogue Grammar in Kam. International Journal of Academic Research, 6, 299-310. https://doi.org/10.7813/2075-4124.2014/6-2/B.45

Skelton, J. (1988). The Care and Maintenance of Hedges. ELT Journal, 42, 37-43. https://doi.org/10.1093/elt/42.1.37

Trappes-Lomax, H. (2000). Consistency and Cohesion. Language in Use. Edinburgh: IALS, University of Edinburgh.

van Leusen, N. (2007). Description Grammar for Discourse. Unpublished Doctoral Disertation, Nijmegen: Radboud University Nijmegen.

Yang, Q., \& Edmondson, J. A. (1997). The Kam in Ancient Times. In A. S. Abramson (Ed.), Southeast Asian Linguistic Studies in Honour of Vichin Panupong (pp. 325-336). Bangkok: Chulalongkorn University Press.

Yang, T. (2017). A Grammar of Kam Revealed in Its Narrative Discourse. Singapore: Springer. https://doi.org/10.1007/978-981-10-2263-0 